\title{
Telejornalismo a serviço do público: a voz do povo em cena*
}

\section{RESUMO}

Na sociedade do telejornalismo, os noticiários de TV cumprem uma função pública e buscam nos cidadãos que representam a cada edição, ou nas imagens que os jornalistas constroem do público, princípios legitimadores do conhecimento socialmente produzido a cada edição. A proposta nesse texto é evidenciar a colocação da população em cena, como ator social com direito à voz, e analisar em que medida por meio da utilização desse recurso audiovisual, os jornalistas envolvidos com a produção dos telejornais tentam construir vínculos com a audiência, e colocar o telejornalismo a serviço do público. O estudo tem como recorte empírico, para a análise da participação popular, os discursos veiculados nos telejornais de uma emissora local, a TV Alterosa - Juiz de Fora.

\section{PALAVRAS-CHAVE}

Serviço público

Telejornalismo

Popular

\section{ABSTRACT}

In the tele-journalism society, the TV news fulfill a public function and seek among the citizens they represent in each edition, or among the images that journalists construct of the public, principles that legitimate the socially produced knowledge that is generated in each edition. The aim of this text is to evidence the placement of people on the scene, as social actors with the right of expressing a thought, and analyze how far through the use of audiovisual resource, the journalists involved in the production of the TV try to build ties with the audience, and produce the TV newscast to serve the public. The research includes an empirical invstigation of the popular participation, na analysis of the speeches delivered in the news of a local broadcast, TV Alterosa - Juiz de Fora.

\section{KEY WORDS}

Public Service

Tele-Journalism

People

\author{
Iluska Coutinho \\ Professora do Programa de Pós-Graduação em Comunicação da \\ UFJF/MG/BR \\ iluskac@uol.com.br

\section{Jhonatan Mata} \\ Mestrando do Programa de Pós-Graduação em Comunicação da \\ UFJF/MG/BR \\ jhonatanmata@yahoo.com.br
}

Principal meio de informação dos brasileiros, incluindo os jovens ${ }^{1}$, os telejornais cumprem claramente uma função pública em um país marcado pela desigualdade no acesso aos bens de consumo e também a direitos essenciais como educação, saúde e segurança. Seja como orientação nos manuais escritos e mesmo nos rituais que conformam a cultura profissional dos (tele)jornalistas, o público seria idealmente o princípio orientador dos fazeres jornalísticos em TV (Coutinho, 2007), ainda que em muitos casos na condição de audiência presumida ${ }^{2}$.

Em estudo sobre as rotinas profissionais no telejornalismo, Alfredo Vizeu defendeu de forma acertada que o telejornalismo no Brasil é um bem público. Essa premissa envolve o entendimento do caráter de universalidade dos conteúdos jornalísticos veiculados nos telejornais que chegariam a todos os cidadãos, de forma a permitir o acesso mais igualitário possível ao conhecimento. Mais que isso, contudo, a compreensão 
dos telejornais como serviço público implicaria na necessidade de assumir atributos que a esse conceito se relacionam no campo teórico, tais como a diversidade, a independência, e o financiamento público (Fidalgo, 2003, p.14).

Vale dizer que financiamento público não é necessariamente estatal, embora essa vinculação seja freqüente em documentos jurídicos. A falta de clareza sobre o entendimento do que seria um serviço público nesse caso também ganha eco na conformação do sistema brasileiro de radiodifusão, que poderia ser considerada omissa no que se refere aos marcos regulatórios. Estes não explicitam com clareza o papel público que se pretenderia de todas as emissoras de televisão, incluindo as controladas pela iniciativa privada, na medida em que estão são concessionárias de um serviço público. Mais que isso, como ressalta Ramos (2008), o modelo brasileiro de radiodifusão divide os sistemas em público, estatal e privado, o que seria uma formulação inadequada em sua visão.

\section{A sucessão e modo de}

\section{organização das notícias e a mensagem de esperança ao final dos noticiários, tanto em nível local quanto nacional, salientam a função de segurança do telejornal.}

Na visão desse autor de referência sobre políticas de comunicação no Brasil, o estabelecimento de modelos normativos que assegurem a prevalência do público sobre o privado na exploração dos serviços de rádio e televisão ainda é um desafio a enfrentar, desafio que na avaliação dele seriam simples do ponto de vista jurídico, mas de complexidade política. Essa complexidade é potencializada, por um lado pela grande presença de radiodifusores/concessionários de rádio e TV com assento direto no Congresso Nacional, e por outro, pela grande relevância política da emissão de conteúdos, especialmente jornalísticos em uma sociedade como a brasileira.

Na sociedade do telejornalismo, título de livro que reúne trabalhos da rede de pesquisadores do tema
(SBPJor), Alfredo Vizeu e João Carlos Correia argumentam que os noticiários de TV atuariam como um lugar de referência para os brasileiros, colocando em destaque sua função pedagógica, "[...] espécie de orientação nas sociedades complexas que homens e mulheres recorrem para o bem e para o mal" (2008, p.19).

Quando sugerem que o telejornalismo representa um lugar de referência para os brasileiros, Vizeu e Correia (2008) retomam as proposições de Canclini e conferem a este tipo de produção uma função muito semelhante à da família, dos amigos, da escola, da religião e do consumo. A referência nesse caso faria com que os telejornais atuassem como conectores, como um laço estruturante. Dominique Wolton também defende o potencial da TV como produtora e fornecedora de representações e laços sociais e, conseqüentemente, portadora de função referencial.

Qual o caráter da televisão? Reunir indivíduos e públicos que tudo tende a separar e oferecer-lhes a possibilidade de participar individualmente de uma atividade coletiva. É a aliança bem particular entre o indivíduo e a comunidade que faz dessa técnica uma atividade constitutiva da sociedade contemporânea (Wolton, 1996, p. 15).

Wolton acrescenta, ainda, que a TV é uma atividade tão importante quanto o voto nas sociedades democráticas, no que diz respeito à participação coletiva, visto que representaria uma "eleição" contínua e diária. Mas, se o telespectador elege determinado programa e se converte em audiência, também é válido dizer que antes disso, na prática diária do telejornalismo, os profissionais envolvidos elegem enquadramentos de realidade de acordo com a sua visão de mundo, escolhendo e construindo uma determinada realidade. Dentro desse fluxo de experiências particulares, o jornalista teria a função de absorver e ao mesmo tempo repassar suas impressões da realidade, num constante diálogo com o conhecimento adquirido (e que será posteriormente repassado).

Autores como Adelmo Genro, Eduardo Meditsch e Carlos Eduardo Franciscato se constituem em referências importantes para entender o jornalismo como forma de conhecimento, socialmente produzido e validado. No recorte dessa reflexão interessa particularmente iluminar as relações entre telejornalismo e público no processo de construção das narrativas audiovisuais veiculadas cotidianamente. Seja como princípio orientador ou como "financiador" das emissoras / telejornais, na medida em que seus vínculos com o programa representam quantitativamente números de audiência que balizam o mercado publicitário, o teles- 
pectador seria um sujeito ativo na construção telejornalística.

Seja pela escolha das pautas, no cuidado com a linguagem utilizada, ou ainda por meio da inserção direta de personagens populares em cena, o fato é que os telejornais buscam construir uma relação de identificação, um vínculo com o público, que representam na tela. Esse tipo de vínculo foi conceituado por Itânia Maria Mota Gomes (2004) como "modo de endereçamento", e pode ser entendido como tudo aquilo que é característico das formas e práticas comunicativas específicas de um programa. Diz respeito ao "modo como um programa específico tenta estabelecer uma forma particular de relação com sua audiência" (Gomes, 2004).

No caso do telejornalismo local, que oferece recorte empírico para essa reflexão, essa necessidade de criação e manutenção de vínculos se constitui em desafio cotidiano para os jornalistas. Há uma necessidade de "falar" para toda a comunidade, de se fazer entender, que poderia ser relacionada com a função exotérica descrita por Vizeu e Correia (2008). Ao menos em tese haveria uma preocupação dos profissionais de telejornalismo local em promover a "dessacralização" ou "dessegredização" das falas dos enunciadores autorizados do discurso jornalístico.

Dentro desse contexto, caberia então ao telejornal a tentativa paradoxal de mostrar a guerra, os conflitos mais diversos, as mortes e ao mesmo tempo deixar a impressão de que o mundo não está beirando a autodestruição, de que tudo isso se processa dentro dos "padrões de normalidade mundanos", já que o sentimento de segurança é fundamental para o ser humano. A dúvida deve, portanto, ser constantemente varrida do dia a dia, por uma questão de sobrevivência. A sucessão e modo de organização das notícias e a mensagem de esperança ao final dos noticiários, tanto em nível local quanto nacional, salientam a função de segurança do telejornal e tentam deixar o público mais confiante senão no mundo, ao menos na cidade onde vive.

No caso da TV, a imagem dos acontecimentos se apresenta como mediadora icônica dos fatos, ou seja, pretende ser uma representação pela semelhança. Os referentes são os próprios acontecimentos, com seus personagens, suas ações, ainda que sujeitos as necessárias seleções de cunho editorial e mesmo operacional.

O princípio dessa seleção, segundo Bourdieu, é a busca do sensacional, do espetacular "A televisão convida à dramatização, no duplo sentido: põe em cena, em imagens, um acontecimento e exagera-lhe a importância, a gravidade e o caráter dramático, trágico" (Bourdieu, 1996, p. 25).

\section{0 público como personagem dos telejornais}

"Tudo o que acontecer de importante no Brasil vou dar um jeito de colocar no ar". A afirmação do novelista Manoel Carlos é praticamente idêntica à de William Bonner quando define os critérios de noticiablilidade no Jornal Nacional. Segundo a definição de seu editor-chefe, o Jornal Nacional apresenta "o que de mais importante aconteceu no Brasil e no mundo naquele dia". A definição do que seria importante segue, evidentemente, critérios jornalísticos e também editoriais.

Vale lembrar, sobretudo, que o produto oferecido aos telespectadores é uma (re)construção da realidade, operada via coleta de imagens, redação de texto, edição, cujo poder de verdade e de celebração do fato é reforçado muitas vezes pela flexão dos verbos no presente do indicativo. Assim, o que os telespectadores acompanham nos telejornais é, para Coutinho, "uma soma de pequenas tentativas de repetição de alguns fatos, amarrados pelos textos de repórteres e apresentadores, uma "imitação da ação" ou das ações humanas, tal como a definição de Aristóteles para a palavra drama" (Coutinho, 2003, p. 9).

Não é intenção desse trabalho qualquer tentativa de investigação de limites entre real e ficção, numa comparação entre produções consideradas ficcionais como as telenovelas ou objetivas como os telejornais. O êxito popular dos programas de televisão, sejam eles telejornais, telenovelas ou outros, o hibridismo que se configura entre entretenimento e informação, e o envolvimento evidente do seu público nos levam a repensar o papel da teledramaturgia em quaisquer casos.

As possibilidades de comparação aumentam significativamente se levarmos em conta os diversos trabalhos que indicam a origem da telenovela tal qual conhecemos hoje. Em geral, costuma-se considerar que a telenovela provém de vários antecedentes que lhe deram uma ou outra de suas características e que sobre ela atuaram com maior ou menor intensidade. Dentre estes, além das histórias em quadrinhos e do melodrama teatral, destacamos a dramatização radiofônica de fatos reais e, antes, os folhetins que seduziam os leitores a cada edição dos jornais impressos do início do século XX. A aproximação se justifica na medida em que consideramos semelhantes as maneiras de contar tais estórias e na importância do telejornal e 
da telenovela como elementos de envolvimento do público brasileiro com a TV.

A atenção dada à participação popular e os modos e motivos nos quais o popular é inserido no telejornalismo são objetos de nosso estudo. Nos limites desse artigo se estabeleceu um recorte local por meio do qual será analisada a inserção do que poderia ser considerado um "merchandising dramático" no telejornalismo.

Iluska Coutinho analisou em artigo a participação dos populares como sujeitos dotados de direito e/ou lugar de fala no telejornal de maior audiência no país: "Ao aparecer como "falantes", terem suas vozes veiculadas no Jornal Nacional, os entrevistados assumem uma espécie de co-autoria no texto que se constitui em rede nacional [...]" $(2002$, p. 3). Para analisar a diversidade de vozes no telejornal, foram estabelecidos oito grupos de fontes a partir da apresentação feita pelo repórter e das informações apresentadas no vídeo via gerador de caracteres, com a inclusão do nome e cargo: da iniciativa privada; de órgãos públicos e do Poder Judiciário; sindicalistas; do show-business e/ou astros esporte; internacionais; autoridades políticas; populares e experts.

\section{Jornal Nacional apresenta}

\section{"o que de mais importante}

aconteceu no Brasil e no mundo

naquele dia". A definição do que

seria importante segue,

evidentemente, critérios

jornalísticos e também

\section{editoriais.}

O grupo intitulado na análise como "Populares" é formado por pessoas de mais diferentes Estados, classes sociais, níveis culturais. A unidade é estabelecida pelo enfoque das entrevistas, pela forma como a autoridade do cidadão comum é conferida, como experiência vivida. Assim, 32\% do total de entrevistas do programa, no período analisado, têm como tema os aspectos pessoais, privados e quase sempre emocionais com que os entrevistados vivenciaram determinada situação. Ao inserir as narrativas do povo na tela os telejornais acabam por se apresentar como mediação entre a experiência vivida pelo outro, cuja fala aparece na tela e mundo, a vida particular de cada telespectador e suas relações com a sociedade.

Vale ressaltar que na média de tempo registrada ao longo do recorte o ritmo de edição é frenético, e parece garantir apenas 17 segundos de fama, ou de exercício da "cidadania eletrônica". Antônio Cláudio Brasil também destaca a importância de fazer um bom "povo fala" como recurso audiovisual. Segundo ele, "quase todas as matérias de jornalismo na TV sucumbem à eterna tentação de convocar "a voz do povo", também conhecida como "a voz de Deus" (Brasil, 2002, p. 5). Entre as principais vantagens desse recurso para o autor estariam proporcionar credibilidade e aparência de um "universo de pesquisa" e, freqüentemente, compensar a falta de tempo para a apuração jornalística das matérias.

Um livro da antropóloga e jornalista Susan Allen denominado Media Anthropology - Informing Global Citizens, discute o papel da antropologia nos meios de comunicação de massa. Para nosso estudo, é interessante tomarmos emprestada a especulação que a autora faz sobre a proximidade entre a metodologia etnográfica da antropologia e seu lendário "trabalho de campo" e a investigação jornalística, sobretudo no telejornal.

Susan Allen afirma que a maior oportunidade para um envolvimento antropológico nos meios de comunicação de massa como a TV estaria, em verdade na área de produção de notícias e, completa

[...] não necessariamente no segmento que chamamos de hard news, ou notícias quentes do dia-adia, mas naquelas matérias complementares mais explicativas que são tão necessárias para entendermos um mundo totalmente às avessas, repletos de novos personagens saídos de verdadeiras obras de fiç̧ão romanceada, que insistem em se tornar notícia (Allen, Susan apud Brasil, 2002, p. 101).

Nessa perspectiva que visa contribuir para o estabelecimento de um "antropojornalismo", que evite um pensamento reducionista e possa apontar melhores pautas para um novo jornalismo, evidenciou-se o mesmo cenário descrito pela autora em uma pesquisa anterior. Ao analisar a "Dramaturgia do Telejornalismo Regional"3 constatou-se justamente em matérias complementares, a tentativa do telejornal MGTV em sua edição regional, veiculada pela TV Panorama, associar seus "personagens" (com destaque para o "povo fala") a um repertório que possa ser reconhecido por seus telespectadores, gerando identificação com a população juizforana. 
[...] quando seleciona os personagens que irão compor suas narrativas, nas quais predomina a dicotomia bem versus mal, percebemos um padrão que norteia a totalidade das matérias: vilões, vítimas, heróis e mediadores do conflito são 'escalados' rigorosamente de acordo com características próprias (Mata, 2006, p. 6).

Nesse estudo, que abarcava 10 edições do MGTV $1^{a}$ edição, verificou-se que a população era vítima de 90\% das situações-problema. Já o vilão aparece representado por instituições, situações, algo impessoal enquanto entre os mediadores se incluíam, além dos jornalistas, especialistas (médicos, nutricionistas, psicólogos) com predominância da polícia como fonte oficial.

Passados quase três anos da veiculação e análise das matérias, recorreu-se ao mesmo telejornal para observar a caracterização popular no noticiário. A posição de destaque ocupada pelo recurso "povo fala" continuava tendo como modelo a utilização do cidadão como instrumento de personificação de assuntos. Também permanece "intacta" nossa escalação de personagens, dentro do que Coutinho (2003) caracteriza como dramaturgia do telejornalismo, com direito a intrigas, cenários, referências temporais e outros elementos ficcionais.

Um dos motivos de investigação é devido esse tipo de caracterização do representante popular (como vítima das situações romanceadas) tornar-se recorrente nos telejornais locais analisados. Seria esse um modelo hegemônico na tentativa de criação de vínculos locais. Além disso, é importante refletir de que maneira esse recurso e a escalação de papéis no telejornalismo funcionariam como um "laço social", conforme proposto por Dominique Wolton.

Convém aqui acrescentar em nossa discussão as proposições de Pierre Bourdieu sobre a ação simbólica da televisão.

Uma parte dessa ação, no plano das informações, por exemplo, consiste em atrair a atenção para fatos que são de natureza a interessar a todo mundo, dos quais se pode dizer que são omnibus - isto é, para todo mundo. Os fatos-ônibus são fatos que, como se diz, não devem chocar ninguém, que não envolvem disputa, que não dividem, que formam consenso, que interessam a todo mundo, mas de um modo tal que não tocam em nada de importante (Bourdieu, 1996, p. 23).

Sendo assim, a TV poderia, paradoxalmente ocultar mostrando, ou seja, construir uma realidade que, a priori, apresenta uma objetividade que significa "ser justo com as partes envolvidas", mas passa longe da objetividade antropológica, que compreende a fideli- dade à verdade. Bourdieu relaciona a visão de mundo dos jornalistas e a lógica dessa profissão à representação que a mídia dá aos "fenômenos de subúrbio" ou populares. Para o autor, "os jornalistas têm 'óculos' especiais a partir dos quais vêem certas coisas e não outras. Com isso, eles operam uma seleção e uma construção do que é selecionado" (Bourdieu, 1996, p. 25).

\section{Fabricando o Popular}

Além de, em tese, produzir um jornalismo mais participativo, com maior exercício da cidadania, a construção de laços de pertencimento de uma emissora de TV com seu público, nos moldes da indústria cultural, é um processo que pode ser comparado, sem esforço, à fabricação de um produto. Construir uma imagem local e popular implica em investir no reconhecimento, por parte do telespectador, de alguma origem comum, de algo que traga para dentro de casa (via TV), a rua, o bairro, a cidade onde se vive.

Para isso, na redação, cada profissional exerce uma função que terá como resultado um produto final (no sentido mais denotativo possível). $\mathrm{O}$ "povo", nesse contexto, é retratado e se converte em audiência. A criação e manutenção desse vínculo de pertencimento e identidade entre as emissoras locais e regionais e seus públicos é fonte de lucro, também, para as redes, como ressaltou Rogério Bazi ao refletir que "a empresa sabe que é atrás dessa relação estreita com a comunidade que reside a audiência refletida em seus programas e, também, o anunciante" (Bazi apud Coutinho, 2008, p. 99).

Nessa busca por reafirmação do local, a hipótese central da pesquisa cujos resultados são apresentados de forma sintética aqui foi a de que o popular é fabricado. Esse processo começaria na etapa de escolha daquilo que será notícia, dentro do universo dos critérios de noticiabilidade ${ }^{4}$, da linguagem que é direcionada, da definição da emissora sobre quem é seu público dentre outros fatores, entre eles o contemporâneo recurso da interatividade via web, potencializando a participação do público inclusive na sugestão de pautas.

A proposta no recorte da pesquisa apresentado nesse artigo é compreender como essas construções do popular são realizadas no telejornalismo local da TV Alterosa - Juiz de Fora. A emissora é vinculada à TV Alterosa, que tem sede em Belo Horizonte e é afiliada ao SBT. Um dos objetivos da Alterosa, presente na missão da empresa, é de não só informar como ajudar a proporcionar o bem-estar das pessoas.

Além do telejornal, é conveniente citarmos outros projetos pertencentes ao setor de Comunicação da Al- 
terosa, caracterizados pela editora da emissora em Juiz de Fora, Gilse Bara, como formas de aproximação entre TV e público. Em função dessa busca por proximidade com o telespectador, a emissora recebe visitas de estudantes e outras pessoas que queiram conhecer a TV, sugerir pautas e fazer denúncias.

Para facilitar esse acesso, foi criado o Canal da Alterosa. Trata-se de um canal Interativo pelo qual o telespectador entra em contato com a emissora através de um número de telefone disponibilizado pela TV, durante toda a programação. Em tese, é através dele que os telespectadores, além de participarem de enquetes e promoções, sorteio de brindes e ingressos, atuam na construção do telejornal, sugerindo pautas e fazendo denúncias. Por meio desse canal o público pôde concorrer, nas edições que compõem o corpus empírico deste trabalho, a ingressos para uma peça de teatro (sorteados na edição 30/06) e a uma bolsa de couro (anunciada no dia 04/06 e sorteada no dia 05/06).

\section{0 êxito popular dos programas} de televisão, sejam eles telejornais, telenovelas ov outros, o hibridismo que se configura entre entretenimento e informação, e o envolvimento evidente

\section{do seu público.}

Já o Apareça na TV é um projeto que existe desde a implantação da emissora em Juiz de Fora e possibilita que, por meio de agenda prévia, grupos de estudantes, idosos, bombeiros, dentre outros, possam conhecer os departamentos da empresa. De forma sucinta, as funções de cada departamento da TV são apresentadas. A visita termina no estúdio, com o participante lendo o teleprompter no lugar onde ficava a bancada ${ }^{5}$ do telejornal. As visitas são gravadas e, posteriormente, aparecem ao longo da programação, em formato de pequenas inserções veiculadas nos intervalos comerciais com locução em off.

O telespectador acompanha, via TV, imagens dos cidadãos comuns assumindo a antiga bancada, obser- vando as rotinas de produção das notícias e "interpretando" as posturas típicas dos apresentadores de telejornais. As imagens das visitas também são, esporadicamente, inseridas em matérias curtas no telejornal e disponibilizadas na página da emissora na internet.

Nesse sentido, é reforçado o caráter espetacular da TV, colocando-se o telespectador com seus segundos de fama, seu "momento-jornalista" num patamar, que em princípio, lhe seria impossível. Edgar Morin definiria essa estratégia como "potência de projeção"(Morin, 1969). Basicamente, compreende a conformação, e até mesmo o alívio do telespectador por divertir-se num universo idealizado, projetandose no outro, mergulhando em sentimentos de evasão, de compensação, de expulsão, até mesmo de transferência. Também predominam nas emissões relacionadas ao Apareça na TV a função de linguagem definida como conativa ${ }^{6}$. O convite disparado pelo locutor de "Participe você também do Apareça na TV" carrega traços de persuasão e argumentação que marcam o remetente da mensagem, estratégia amplamente utilizada nos campos da publicidade e da propaganda.

O Nossa Gente é outra iniciativa da emissora relacionada à criação de vínculos com seu público. Consiste numa inserção de um minuto, mostrando pessoas que não são famosas, mas se destacaram por alguma atitude pioneira, pelo espírito de solidariedade ou vanguardista convertido em ação em suas comunidades, bairros, cidades. As "nossas gentes" são na maioria das vezes sugeridas por moradores da região a que pertencem e têm seus feitos investigados pela equipe da $\mathrm{TV}$, antes da produção do vídeo.

A construção da imagem do herói assume aqui seu apogeu explícito, para realizar, de acordo com o que sugere o texto dos vídeos produzidos "uma homenagem aos que engrandecem nossas comunidades". Os heróis do povo são mediatizados via telinha com a utilização dos mais variados recursos icônicos. Cumprese à risca o essencial do modelo narrativo, que é girar em torno das ações de um personagem para atingir seus objetivos. A temporalidade, típica das narrativas televisivas, é explorada de forma a possibilitar ao telespectador o conhecimento sobre os desdobramento da vida de Dona Maria José, de Seu Antônio e de outros ilustres (des)conhecidos e todas as provações e atos de coragem pelos quais passaram até se tornarem heróis da comunidade, da "nossa gente".

Os atos de bravura concentram-se am atitudes que beneficiaram determinada população como a criação de um hospital, ajuda aos pobres, vocação para o magistério, fundação de faculdades, dentre outros, e se 
conjugam com a natureza de prestação de serviços do telejornal da Alterosa. O código sonoro é um aliado dessa narrativa e um dos grandes responsáveis pela reação emotiva dos telespectadores diante da saga do herói. A ambientação sonora é alicerçada, sobretudo, em clássicos e tristes BG's.

A interação entre público e emissora se realiza ainda por meio da promoção constante de eventos pela emissora na cidade de Juiz de Fora, como passeios ciclísticos. Esses eventos são sempre noticiados pelo telejornal, reforçando o vínculo entre TV e sociedade juizforana/regional. Os slogans da Alterosa, idealizados pelo departamento de comunicação da emissora de Belo Horizonte, tentam reforçar o vínculo com o telespectador, enfatizando a mineiridade e a valorização do público.

Até hoje, foram criados três slogans: $\mathrm{O}$ primeiro deles, "Na nossa frente só você" remete ao telespectador, que estaria, nesse contexto, à frente da TV, em posição privilegiada ou à frente da TV, como aquele que assiste do sofá à programação, numa conceituação denotativa do sentido da frase. O slogan "Muito mais Minas" aguça a tentativa da Alterosa (nome que inclusive é o apelido das "Minas Gerais" ou "Alterosas") em se afirmar como a emissora popular do mineiro. O atual slogan foi definido com o auxílio do público. O Departamento de Comunicação realizou campanha onde três opções de slogans eram oferecidas ao telespectador. Através de ligações telefônicas e votações pelo site da Alterosa Matriz, localizada na capital, elegeu-se o slogan "A TV que o mineiro vê".

A internet, embora incluída no "arsenal interativo" da Alterosa JF, tem restrições em decorrência da criação do site juizforano ter sido muito recente (agosto de 2007) e da situação de exclusão digital que atingiria significativa parcela de seu público, formado por espectadores especialmente das classes C, D e E de acordo com a editora do telejornal. Com isso, fica também prejudicada a sugestão de pautas e outros contatos por e-mail, o que provoca o predomínio do canal interativo telefônico e das visitas à sede da emissora como formas de acesso do público local/regional à TV.

\section{Considerações finais}

Num universo de 41 matérias produzidas pelo Jornal da Alterosa, em nosso recorte empírico, 34 abordavam temáticas amenas, sendo que destas, 31 envolviam a participação popular na construção da narrativa, com 16 matérias incluindo crianças e adolescentes no vídeo. As outras sete produções apresentavam temáticas trágicas ou tristes, ou as hard news na concepção de Susan Allen anteriormente apresentada, e se voltavam, sobretudo, para a necessidade de solução de problemas com a prestação de serviços públicos. Nas sete matérias "difíceis", em quatro houve participação popular como personagem/povo fala.

Para esse artigo optou-se por destacar a contribuição das crianças que surgem como heróis e/ou mocinhos nas narrativas identificadas como notícias positivas, no papel de personagens ou povo-fala. São elas que apontam "a Juiz de Fora que querem", sem poluição, com menos violência e feliz, conforme a matéria de 31/05, sobre o aniversário da cidade; aprendem a conviver com o diabetes $(02 / 06)$; são a esperança da cidade e orgulho dos pais ao se esforçarem nos treinos para o Festival de Ginástica de Trampolim (03/06); embarcam no mundo das palavras, no Festival de Leitura (04/06); dão lição de cidadania participando de Gincana Ambiental (05/06).

Convém lançar um olhar mais detalhado sobre a matéria de $02 / 06$, sobre "Crianças e adolescentes que têm diabetes e aprendem a conviver com a doença". A confirmação da tese de Coutinho (2003) sobre a apropriação da dramaturgia por parte do jornalismo de TV se configura por meio de diferentes recursos. Primeiramente no que tange aos "conflitos externos típicos do drama" (Pallottini, 1989, p. 81). Estes se compõem dos obstáculos encontrados pelo personagem no caminho de sua vontade ou de seus desígnios. Na notícia selecionada, o diabetes é a outra vontade do drama, o vilão impessoal, que deseja impedir o protagonista-mocinho de alcançar seu alvo, que no caso da criança, seria ter uma vida "normal", mesmo com a doença. A repórter inicia o VT ambientando o telespectador para a estória que será contada, apresentando o personagem que representa, nessa narrativa, o lado do bem.

Johnatan tem apenas 11 anos e desde os cinco aprendeu a checar o nível de glicose no sangue. Ele tem diabetes do tipo 1 e precisa ficar atento aos hábitos alimentares. Quando vai a uma festa de aniversário, por exemplo, o estudante tem que resistir às tentações.

O público recebe as primeiras imagens da criança num exercício de sensibilização e identificação repassado pelo repórter pela adjetivação (apenas 11 anos) e pelos obstáculos que a doença confere numa atividade comum ao universo infantil: as festas de aniversário. Na sonora, Johnatan explica que é preciso ter "cuidado, senão o diabetes pode subir e eu passar mal".

Já a adolescente Ana Carolina Silva, convive com o diabetes por um motivo mais trágico: o abalo emocio- 
nal causado pela morte do pai, com a mesma doença, teria desencadeado a sua enfermidade. Em sua sonora, ela retransmite a imagem positiva do primeiro entrevistado, ao advertir que a doença: "Não é um bicho de 7 cabeças, é só controlar e saber conviver". As mães destas e de outras crianças aparecem como personagens secundários, apresentando à narrativa um subvilão: as despesas com o tratamento dietético de seus filhos. Uma das mães, Vera Lúcia Leal, reclama que "as coisas diet é tudo muito caro, pesa né?". A repórter abraça a causa da mãe e se insere no conflito em sua passagem:

A Vera Lúcia tem razão para se preocupar. Uma pessoa com diabetes do tipo 1 gasta, em média por mês, 400 reais com o material para fazer o controle da doença e para uma dieta especial. Por isso foi criado o Pólo de atendimento em diabetes para crianças e adolescentes em Juiz de Fora.

\section{Sendo assim, a TV poderia, paradoxalmente ocultar}

\section{mostrando, ou seja, construir uma realidade que, a priori, apresenta uma objetividade que significa "ser justo com as partes envolvidas".}

Médicos e nutricionistas aparecem como mediadores, recomendando tratamentos e explicando sobre a doença, enquanto as crianças mostram-se guerreiras de otimismo. Lutando contra uma enfermidade associada a adultos, com as privações impostas nas festas de aniversários e convivendo com traumas ainda maiores, como a morte do pai, os heróis nessa seleção audiovisual se assemelham aos heróis da tragédia grega. Ambos são postos em situação de ter que enfrentar os desígnios da fatalidade e do destino. E, quanto mais se acrescentam desafios a esses personagens nos seus esforços por ultrapassar os obstáculos, mais parece crescer sua própria força.

A questão principal a ser destacada no JA Edição Regional é exatamente o fato de que esse caráter híbrido público-fonte tem suas particularidades, de acordo com sua editora. O veículo aposta em uma imagem - construída interna e externamente através das práticas de produção - de porta-voz, representante oficial do grupo de telespectadores. O Canal da Alterosa, os projetos da Comunicação, a própria missão da empresa reforçam essa tese. Entretanto, é nítido, no período analisado, o fato de as fontes populares juiz foranas serem ouvidas predominantemente nas soft news, pelo motivo destas também serem prioritárias no cardápio visual do noticiário durante o período analisado.

Também é preciso levar em conta que a utilização das fontes populares, mais que estratégia para garantir o espaço mercadológico do telejornal, parece ser um importante ponto de apoio para a constituição profissional dos produtores. O contato com o público escolhido entre classes socialmente não-privilegiadas parece reforçar nos jornalistas a ideologia que estabelece na proteção dos interesses e na representação dos dominados a função social da profissão. Aqui, não apenas o telejornal, com a resolução de problemas que a princípio remetem ao poder público, como também o Canal Interativo e, sobretudo o projeto Apareça na TV e seu poder de catarse, constituem-se em exemplo desse tipo de prática.

Gilze Bara define notícia da seguinte forma: "A gente se coloca muito como público para ter esse tino do que vai interessar ou chocar. É muito intuitivo. Sou defensora dessa linha, edição é uma coisa extremamente pessoal. Eu sou intuitiva demais. Tenho meu olhar de editora, mas também de telespectadora". Esse método (ou ausência do mesmo) se aproxima daquilo que Traquina defende como "iluminação do jornalismo", com a qual os profissionais buscam vincular suas escolhas ao "talento", "faro jornalístico".

Retornando à discussão sobre a importância dos critérios de noticiabilidade relativos ao público, verificamos que a imagem que os jornalistas têm da audiência é um critério bastante usado pelos profissionais quando querem explicar por que escolheram determinado fato.

Em síntese, na produção do programa local tomado no recorte empírico deste trabalho, seja na rotina de seleção que é assumida por sua editoria como intuitiva, ou ainda na forma de apresentação da notícia, que inclui os populares como personagens, os telejornais parecem se colocar a serviço do público. Afinal, é exatamente por meio dessa relação de sedução e simbiose que o telejornalismo garante sua própria sobrevivência, financeira quando o público se converte em audiência, e política por meio da legitimidade que teria como espécie de fiança a aprovação do telespectador $\square$ FAMECOS 


\section{REFERÊNCIAS}

BARA, Gilze. Gilze Bara: depoimento [jun. 2008]. Entrevistador: Jhonatan Alves Pereira Mata. Juiz de Fora, 2008. 1 fita cassete (60 $\mathrm{min})$ : mono.

BOURDIEU, Pierre. Sobre a televisão. Rio de Janeiro: Zahar, 1996.

BRASIL, Antônio Cláudio. Telejornalismo, Internet e guerrilha tecnológica. Rio de Janeiro: Ciência Moderna, 2002.

COUTINHO, Iluska. Democracia eletrônica e televisão no Brasil: Os telejornais como espaço de disputa por hegemonia política e cultural. Anais do XI Congresso da Compós. Rio de Janeiro: UFRJ, 2002. CD’Rom.

. Dramaturgia do telejornalismo brasileiro: a estrutura narrativa das notícias em TV. Tese [doutorado] em Comunicação Social. Universidade Metodista de São Paulo. São Bernardo do Campo, 2003.

GOMES, Itânia Maria Mota. Das utilidades do conceito de endereçamento para análise do telejornalismo. Rio de Janeiro: E-papers, 2004.

MATA, Jhonatan Alves Pereira. Vícios e virtudes no telejornalismo local: uma análise dos personagens no

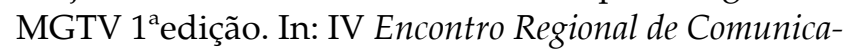
ção, 2006, Juiz de Fora. Anais... Juiz de Fora: UFJF, 2006. CD-ROM.

MORIN, Edgar. Cultura de Massas no século XX: o espírito do tempo. Rio de Janeiro: Forense Universitária, 1969.

PALLOTTINI, Renata. Dramaturgia: A Construção do Personagem. São Paulo: Ática, 1989.

RAMOS, Murilo César. Reestruturação do sistema e controle público. Laboratório de Políticas de Comunicação. Brasília: UnB. Mimeo.

VIZEU, Alfredo Eurico. O lado oculto do telejornalismo. Florianópolis: Calandra, 2005.

VIZEU, Alfredo Eurico \& CORREIO, João Carlos. A construção do real no telejornalismo: do lugar de segurança ao lugar de referência. In VIZEU, Alfredo(Org.). A Sociedade do Telejornalismo. Petrópolis:Vozes, 2008.

WOLTON, Dominique. Elogio do grande público: uma teoria crítica da televisão. São Paulo: Ed. Ática, 1996.

\section{NOTAS}

*Trabalho apresentado no VI SBPJor - Encontro Nacional de Pesquisadores em Jornalismo, em São Bernardo do Campo, SP, 2008.

${ }^{1}$ Segundo matéria publicada em http:// www.comunique-se.com.br: $80 /$ index.asp? $p=$ Conteudo/NewsShow.asp\&p2=idnot $\% 3 \mathrm{D} 46031 \% 26$ Editoria\%3D8\%26Op2\%3D1\%26Op3\%3D0\%26pid\% 3D617671609\%26fnt\%3Dfntnl a TV é o meio de informação mais procurado por jovens de 16 a 25 anos segundo dados do Datafolha. A pesquisa foi realizada entre os dias 1 e 2 de abril e ouviu 1541 jovens em 168 municípios brasileiros.

${ }^{2}$ Sobre a hipótese da audiência presumida ver Alfredo Vizeu (2005), "O lado oculto do telejornalismo".

${ }^{3}$ Pesquisa realizada entre janeiro de 2005 e 2007 com o apoio da Fapemig, e bolsas de Iniciação Científica da UFJF e Pibic-CNPq.

${ }^{4}$ Restrições ligadas à organização do trabalho jornalístico, sobre as quais se criam convenções profissionais, para definir o que é notícia.Englobam desde o uso das fontes até à seleção dos acontecimentos.Impacto sobre a nação, interesse coletivo e quantidade de pessoas envolvidas no fato são exemplos destes critérios.

${ }^{5}$ Atualmente a âncora do Jornal da Alterosa Edição Regional apresenta o telejornal de pé.

${ }^{6}$ Do latim conatum, que significa tentar convencer alguém através de um esforço. 